\title{
Congenital Spondylolysis, Lumbosacral Region
}

National Cancer Institute

\section{Source}

National Cancer Institute. Congenital Spondylolysis, Lumbosacral Region. NCI Thesaurus. Code C34502.

A defect in the pars interarticularis of the vertebral arch of a lumbar or sacral vertebra that is present at the time of birth. 